ORIGINAL ARTICLES

\title{
EPIDEMIOLOGICAL PROFILE OF PANDEMIC INFLUENZA A (H1N1) 2009 AT DHAKA MEDICAL COLLEGE HOSPITAL
}

\author{
QUAZI TARIKUL ISLAM ${ }^{1}$, AZIZUL KAHHAR ${ }^{1}$, SYED MOHAMMAD ARIF ${ }^{2}$, AHMEDUL KABIR ${ }^{3}$, KHAN \\ MOHAMMAD ARIF ${ }^{4}$, GOLAM KIBRIA ${ }^{5}$, NARAYAN CHANDRA SAHA ${ }^{6}$, MD MAHMUDUR RAHMAN \\ SIDDIQUI ${ }^{7}$, MD SHAHRIAR MAHBUB ${ }^{7}$, HAM NAZMUL AHASAN $^{1}$, BAZLE QUADER ${ }^{8}$
}

\begin{abstract}
The first case of 2009 pandemic influenza A (H1N1) virus infection in Bangladesh was documented on June 18. Subsequently, persons with suspected cases of infection and contacts of those with suspected infection were tested. Individuals in whom infection was confirmed were hospitalized and quarantined, and some of them were closely observed for the purpose of investigating the nature and duration of the disease. In Dhaka Medical College Hospital, there were 28 admitted patients in flu ward and 2335 registered suspected H1N1 influenza cases attended in flue corner but 833 highly suspected cases were recorded in case record form. We describe the epidemiological characteristics of 28 indoor (flu ward) and 833 outdoor (flu corner) patients. Most of them were in between 20 to 30 years age group. Among 833 outdoor patients 611(73.34\%) were male and 222(26.65\%) were female. $354(42.49 \%)$ patients were student, 195 $(23.40 \%)$ were service holder. No patients (indoor) had any serious underlying medical conditions.
\end{abstract}

Keyword: Pandemic influenza A (H1N1), Dhaka Medical College Hospital, Bangladesh, epidemiology.

\section{Introduction}

World Health Organization (WHO) announced pandemic alert level 6 on 11th June, 2009. ${ }^{1}$ In less than 20 days this alert level was raised from 5 to 6 and now the infection has spread to 208 countries all over the world with 2,46,571 confirmed cases and 9596 deaths. $^{2}$ Level 6 indicates widespread human infection where a global pandemic is ensuing. ${ }^{3}$ This is the first influenza pandemic since 1968 when the influenza A (H3N2) swept across the world. ${ }^{4}$ In late April, 2009 it was confirmed in Mexico and the United states that a novel influenza virus with unique genetic and antigenic characteristics has emerged. ${ }^{5}$ The 2009 H1N1 virus is a triple-reassortant influenza virus containing genes from human, swine, and avian influenza viruses. ${ }^{6,7,8}$ Now the virus is spreading from person-to-person in multiple countries in Europe, the Americas and the Far East. ${ }^{15}$ For the first time in history, health authorities around the world are watching the situation very closely with "real-time" data on outbreak emanating from every corner of the world. ${ }^{15}$ This can be attributed to the synchronous and prompt sharing of information unlike the early days of SARS

1. Professor, Department of Medicine, Dhaka Medical College

2. Associate Professor, Department of Medicine, Dhaka Medical College

3. Assistant Professor, Department of Medicine, Dhaka Medical College

4. Indoor Medical Officer, Department of Medicine, Dhaka Medical College

5. Resident Physician, Department of Medicine, Dhaka Medical College

6. Associate Professor, Department of Pediatrics, Dhaka Medical College

7. Postgraduate resident, Department of Medicine, Dhaka Medical College

8. Director, Dhaka Medical College Hospital, Dhaka

Correspondence: Prof. Quazi Tarikul Islam, Department of Medicine, Dhaka Medical College, E-mail: prof.tarik@gmail.com 
outbreak in China in 2003. ${ }^{9,15}$ The first case of swine flu in Bangladesh was detected on 18th June, 2009. In Bangladesh there were 803 confirmed cases of H1N1 infection and among them only 6 patients died. ${ }^{10}$

All patients with confirmed infection and suspected severe infection had been hospitalized and quarantined in an isolated Flu ward in the Dhaka Medical College Hospital to isolate them from the general population. The hospital quarantine allowed us to closely monitor the patients, its clinical features, the results of laboratory and radiographic tests, and the nature and extent of the disease. This report describes the epidemiologic characteristics of the 28 indoor (at Flu ward) and 833 outdoor (at Flu corner) patients at Dhaka Medical College Hospital from August to November 2009 of pandemic influenza A (H1N1) virus infection.

\section{Materials \& Methods}

This was a cross sectional study. The study was done on highly suspected 833 recorded outdoor (flu corner) and 28 indoor patients admitted in Flu ward of Dhaka Medical College Hospital during the study period of August to November 2009. A datasheet was made and filled up with recording of all relevant parameters. It was then assessed and evaluated. Results were analyzed by using statistical software program SPSS version 12. A suspected case was defined as an influenza-like illness (temperature $\geq 37.5^{\circ} \mathrm{C}$ and at least one of the following symptoms: sore throat, cough, rhinorrhea, or nasal congestion) and either a history of travel to a country where infection had been reported in the previous 7 days or an epidemiologic link to a person with confirmed or suspected infection in the previous 7 days. A confirmed case was defined by a positive result of a real-time reverse-transcriptase- polymerase-chainreaction (RT-PCR). The National Rapid Response Team (NRRT) is investigating all reported cases. The Institute of Epidemiology, Disease Control and Research (IEDCR) \& National Influenza Centre (NIC) has taken the lead role in conducting preliminary laboratory investigation with Real Time- PCR (RTPCR) of nasopharyngeal or pharyngeal swab. A close contact was defined as a person who lived with or was exposed to the respiratory secretions or other bodily fluids of someone with suspected or confirmed infection. Patients were followed until discharge, with symptoms and signs recorded daily. The details of all investigations and treatments were recorded. A return to normal body temperature was defined as a temperature of less than $99^{\circ} \mathrm{F}$ for 12 hours after the withdrawal of any antipyretic treatment. The criteria for discharge (as defined in the guideline) were two readings of normal body temperature taken on 2 consecutive days, the absence of respiratory symptoms, and negative results on the testing of samples from two consecutive pharyngeal or nasopharyngeal swabs.

\section{Results}

Table I

Sex distribution of indoor patients $(n=28)$

\begin{tabular}{lcc}
\hline Sex & Number $(\mathrm{n})$ & Percentage $\%$ \\
\hline Male & 9 & $32.14 \%$ \\
\hline
\end{tabular}

Table-I shows, out of 28 indoor patients, 19 (67.85\%) were female and only 9 (32.14\%) were male patients.

Table II

Age distribution of indoor patients $(n=28)$

\begin{tabular}{lcc}
\hline Age range & Number $(\mathrm{n})$ & Percentage $\%$ \\
\hline$<10$ & 2 & $7.14 \%$ \\
$11-20$ & 7 & $25 \%$ \\
$21-30$ & 11 & $39.28 \%$ \\
$31-40$ & 3 & $10.71 \%$ \\
$41-50$ & 4 & $14.28 \%$ \\
$51-60$ & 1 & $3.57 \%$ \\
\hline Total $]$ & 28 & $100 \%$ \\
\hline
\end{tabular}

Table II shows, age distribution of indoor patients varied from $<10$ to 60 years. Maximum numbers of the patients were in the age group of 21-30 years (39.28\%).

Table III

Coexisting condition of indoor patients $(n=28)$

\begin{tabular}{lcc}
\hline Coexisting condition & Number(n) & Percentage (\%) \\
\hline Diabetes Mellitus & 3 & $10.71 \%$ \\
Hypertension & 1 & $3.57 \%$ \\
Bronchial Asthma & 2 & $7.14 \%$ \\
Pregnancy & 3 & $10.71 \%$ \\
No significant coexisting & 19 & $67.85 \%$ \\
condition & & \\
\hline
\end{tabular}

Table III shows, 3 (10.71\%) patients were diabetic and $3(10.71 \%)$ were pregnant. 
In our outdoor (Flu corner) at Dhaka Medical College Hospital (DMCH), 2335 registered suspected H1N1 influenza cases were attended but 833 highly suspected cases were recorded in case record form (CRF). They were all enlisted, registered, thorough histories were taken and clinical examinations were done. Suspected cases were sent to IEDCR for PCR from nasopharyngeal swab to detect Influenza A H1N1. Confirmed and admittable cases were admitted in Flu ward of DMCH. Subsequent follow up of the outdoor patients was not possible, because many of them did not report to us for further follow up.

\section{Table IV}

Age and sex distribution of outdoor (flu corner) patients $(n=833)$

\begin{tabular}{lccc}
\hline Age group & Number & \multicolumn{2}{c}{ Gender } \\
\cline { 3 - 4 } & $(\%)$ & Male (\%) & Female (\%) \\
\hline $0-4$ & $11(1.32)$ & $4(0.48)$ & $7(0.84)$ \\
$5-9$ & $20(2.40)$ & $11(1.32)$ & $9(1.08)$ \\
$10-14$ & $29(3.48)$ & $13(1.56)$ & $16(1.92)$ \\
$15-19$ & $131(15.72)$ & $91(10.92)$ & $40(4.80)$ \\
$20-24$ & $311(37.33)$ & $247(29.65)$ & $64(7.68)$ \\
$25-29$ & $144(17.28)$ & $113(13.56)$ & $31(3.72)$ \\
$30-34$ & $69(8.28)$ & $49(5.88)$ & $20(2.40)$ \\
$35-39$ & $43(5.16)$ & $23(2.76)$ & $20(2.40)$ \\
$40-44$ & $32(3.84)$ & $26(3.12)$ & $6(0.72)$ \\
$>44$ & $43(5.16)$ & $34(4.08)$ & $9(1.09)$ \\
\hline Total (\%) & $833(100 \%)$ & $611(73.34 \%)$ & $222(26.65 \%)$ \\
\hline
\end{tabular}

Table IV shows, among 833 outdoor patients $611(73.34 \%)$ were male and $222(26.65 \%)$ were female. Most patients were in 20-24 years age group, where out of $311(37.33 \%)$ patients $247(29.65 \%)$ were male and $64(7.68 \%)$ were female. Next most populated group was 25-29 years age group, where the total patient were 144 (17.28\%).

Table V

Occupational distribution of outdoor patients $(n=833)$

\begin{tabular}{lcc}
\hline Occupation & Number & Percentage (\%) \\
\hline Student & 354 & $42.49 \%$ \\
Service holder & 195 & $23.40 \%$ \\
Businessman & 92 & $11.04 \%$ \\
House wife & 84 & $10.08 \%$ \\
Children & 30 & $3.60 \%$ \\
Farmer & 3 & $0.36 \%$ \\
Other & 75 & $9.00 \%$ \\
\hline Total & 833 & $100 \%$ \\
\hline
\end{tabular}

Table V shows, out of 833 outdoor patient, 354 (42.49\%) patients were student, 195 (23.40\%) were service holder and 92 (11.04\%) were businessman.

\section{Discussion}

We describe a study of 28 indoor patients and 833 outdoor patients at Flu ward and Flu corner of DMCH for 2009 pandemic influenza A (H1N1) virus infection between August and November 2009. As compare to the recent study of Dr. Bin cao, our majority groups of patients were also in between 21-30 years of age group. ${ }^{11}$ In indoor patients group maximum patients were female $(67.85 \%)$ but in outdoor patients group maximum patients were male. Among 833 outdoor patients $611(73.34 \%)$ were male and $222(26.65 \%)$ were female. Most patients were in between 20-24 years age group, where out of $311(37.33 \%)$ patients 247 $(29.65 \%)$ were male and $64(7.68 \%)$ were female. Male preponderance was also reported by other studies. ${ }^{6,7,11,12,13,14}$ Out of 833 outdoor patients, 354 (42.49\%) patients were student, 195 (23.40\%) were service holder and 92 (11.04\%) were businessman. Among outdoor patients between the age group of 20-29 years total patients were $455(54.62 \%$ ) among them 17 patients had history of contact abroad and 51 patients had contact with flu patients. Indoor patients presented with mostly fever $(92.85 \%)$, rhinorrhea $(71.42 \%)$, shortness of breath (89.28\%) and cough (64.28\%). Where Out of the 833 outdoor patients 596(71.54\%) patients had fever, 585(70.22\%) had cough, 410(49.21\%) had rhinorrhea and $314(37.69 \%)$ had sore throat. Dealing of such a pandemic in a low-resource setting like Bangladesh it would be very difficult task for us. But we have done a great job because with these limited resources only 2 patients had died.

Most cases can be dealt at home by following measures like social distancing, respiratory "etiquette", hand hygiene and household ventilation. ${ }^{15}$ In health-care settings, a system of triage, patient separation, prioritization of use of antiviral medicines and personal protective equipment (PPE) according to risk of exposure, and patient management should be in place. ${ }^{15} \mathrm{~A}$ particular vulnerable group is the pregnant women who have an increased probability of developing complications compounded by the fact that maternal health care is often neglected in these low income countries. ${ }^{1}$ In our indoor patients 3 of them were pregnant but there ultimate outcome were good. The 
Government of Bangladesh (GOB) has taken appropriate measures in combating this pandemic. Screening of passengers at airport, seaport and land ports has begun. Antiviral drugs and PPE have been stockpiled up to the district levels. Isolation units at 29 district hospital have been setup and by the end of the year all district hospitals will have this facility ready. At the national level, National Institute of Chest Disease Hospital (NIDCH) and Infectious Disease Hospital is prepared to manage emergency. Adequate numbers of health professionals have been trained on influenza epidemic. ${ }^{16}$

\section{Conclusion}

Influenza pandemic is not a new phenomenon to the world. Proactive measures rather than panic are warranted in dealing with this problem of global scale. Concerted efforts will help mitigate the damage it will leave on its trail. Perhaps, Dr Chan has summed it up nicely - "We are all in this together, and we will all get through this, together."1

\section{References}

1. World Health Organization. Statement to the press by WHO Director-General Dr Margaret Chan. WHO: 2009. Availableat: http://www.who.int/mediacentre/ news/state- ments/2009/h1n1_pandemic _ phase6_200 0611/en/index.html. Accessed 18th December, 2009.

2. World Health Organization. Laboratory-confirmed cases of new influenza A (H1N1) as officially reported to WHO by States Parties to the International Health Regulations (2005). WHO: 2009. Available at: http://www.who.int/csr/don/2009_12_11a/en/ index.html. Accessed 18th December, 2009.

3. World Health Organization. Influenza A(H1N1): frequently asked questions. Available at: http:// www.who.int/csr/disease/swineflu/frequently asked_questions/en/ . Accessed 18th December, 2009.

4. Cumming N, Jacobs A, Otterman S. WHO Raises Alert Level as Flu Spreads to 74 Countries. The New York Times. June 11, 2009. Available at: http:/ /www.nytimes.com/2009/06/12/world/12who.html? $\mathrm{r}=2$. Accessed $18^{\text {th }}$ December, 2009.
5. Miller MA, Viboud C, Balinska M. The Signature Features of Influenza Pandemics - Implications for policy. NEJM 2009;360:2595-2598.

6. Novel Swine-Origin Influenza A (H1N1) Virus Investigation Team. Emergence of a novel swineorigin influenza A (H1N1) virus in humans. N Engl J Med 2009; 360:2605-15.

7. Trifonov V, Khiabanian H, Greenbaum B, Rabadan $R$. The origin of the recent swine influenza $A(H 1 N 1)$ virus infecting humans. Euro Surveill 2009;14:pii=19193.

8. Ahasan HAMN. Pandemic (H1N1) 2009 influenza: Bangladesh Perspective. J Bangladesh Coll Phys Surg 2009;27:129-131.

9. Malcolm Moore. China suspected of covering up bird flu outbreak. The Daily Telegaph. 4 Feb, 2009. Available at:http://www.telegraph.co. uk/news/ worldnews/asia/china/4510840/China-suspectedofcovering- up-bird-flu outbreak.html. Accessed $18^{\text {th }}$ December, 2009.

10. Institute of Epidemiology, Disease Control and Research. Situation of Influenza A H1N1 (Swine Flu). IEDCR.15 December 2009.

11. Bin C, Xing WL, Mao Y et al. Clinical features of the initial cases of 2009 pandemic influenza A (H1N1) virus infection in China. N Engl J Med 2009;361.111.

12. Human infection with new influenza A (H1N1) virus: clinical observations from a school-associated outbreak in Kobe, Japan, May 2009. Wkly Epidemiol Rec 2009;84:237-44.

13. Komiya N, Gu Y, Kamiya $\mathrm{H}$ et al. Clinical features of cases of influenza A (H1N1) v in Osaka prefecture, Japan, May 2009. Eurosurveillance 2009;vol14;29: 1-3.

14. Roelio PP, Daniela DLRZ, Samuel PL et al. Pneumonia and respiratory failure from Swineorigin Influenza A (H1N1) in Mexico. N Engl J Med 2009;361:680-9.

15. Islam QT. Swine Flu. JOM 2009;10:2:38-39.

16. Institute of Epidemiology, Disease Control and Research. Situation of Influenza A H1N1 (Swine Flu). IEDCR;2009. 